\title{
Estudo morfológico e histomorfométrico sobre variações sazonais do ducto deferente de codorna da variedade italiana
}

Katia Aparecida da Silva VIEGAS ${ }^{1}$

Antonio Marcos ORSI ${ }^{2}$

Karina SIMÕES ${ }^{3}$

Correspondência para:

KATIA APARECIDA DA SILVA VIEGAS

Instituto de Biociências

Departamento de Anatomia

Universidade Estadual Paulista

Distrito de Rubião Júnior, s/n

18618-000 - Botucatu - SP

kaviegas@usp.br

Recebido para publicação: 25/10/2004 Aprovado para publicação: 13/02/2006

1 - Departamento de Cirurgia da Faculdade de Medicina Veterinária e Zootecnia da Universidade de São Paulo, São Paulo - SP

2 - Departamento de Anatomia do Instituto de Biociências da Universidade Estadual Paulista, Botucatu - SP

3 - Centro de Ciências da Saúde da Universidade Metodista de Piracicaba, Lins - SP

\section{Resumo}

No outono o ducto deferente de codorna da variedade Italiana foi observado como um ducto simples, delgado e retilíneo em toda a sua extensão. Assim sendo, secções histológicas transversais deste ducto mostraram-no com forma circular, sendo revestido por epitélio pseudoestratificado cilíndrico que forma pregas longitudinais. Essas pregas adentravam o lúmen tubular, que aparecia freqüentemente vazio de espermatozóides. Porém, no inverno, primavera e verão a aparência morfológica do ducto deferente era a de um túbulo grandemente enovelado. Logo, cada secção histológica transversal do ducto deferente, ao longo de toda a sua extensão, mostrava-se estruturada como secções tubulares dispostas paralelamente entre si. Estas secções tubulares apareciam irregulares quanto à forma e variáveis em número, estando interconectadas por tecido conjuntivo frouxo adventicial. Nestas observações no inverno, primavera e verão o lúmen tubular vaso-deferencial estava totalmente preenchido por espermatozóides e fluido seminal. Portanto, pôde-se concluir, inclusive com base em estudo prévio sobre a cinética testicular nesta variedade Italiana de codorna, que a produção de espermatozóides bem como a sua emissão, estocagem e ejaculação através do ducto deferente não cessam ao longo da maior parte do ano, exceto no outono a etapa quiescente do ciclo reprodutivo circum-anual desta ave doméstica.

\section{Introdução}

Alguns estudos macro e microscópicos sobre o ducto deferente de aves foram realizados, dando ênfase à sua topografia e definindo-o como um tubo longo e serpentiniforme, contínuo à extremidade distal da região epididimária, a partir da qual se continua para além da porção caudal do testículo, posicionando-se ventralmente aos rins e dirigindo-se caudalmente para a cloaca onde se abre no urodeo ${ }^{1,2,3,4,5,6}$.

Estudos morfométricos no sistema vetor extratestricular de codorna da variedade japonesa, consideraram que o ducto deferente ocupa aproximadamente $66 \%$ do volume tubular total dos ductos extratesticulares, contendo a maior parte dos espermatozóides extragonadais (92,3\%), e que os espermatozóides gastam o maior tempo (22,2 horas) para percorrê-lo totalmente, comparativamente com os outros ductos da via espermática ${ }^{7}$. No ducto deferente de codorna doméstica da variedade japonesa foram verificadas variações sazonais significativas no diâmetro tubular e na altura do epitélio de revestimento. Os maiores valores daquelas variáveis foram observados em março e abril e os menores valores de outubro a 
fevereiro, contudo, não ocorreram variações significativas no epitélio de revestimento vaso-deferencial ${ }^{8}$.

Em observação preliminar no ducto deferente de codorna da variedade italiana ${ }^{9}$, notaram-se os menores valores para as variáveis antes caracterizadas nos meses de outono, principalmente de final de março a meados de abril. Por outro lado, o assunto parece ser polêmico, uma vez que com base em estudos espermatogenéticos caracterizou-se, na variedade japonesa de codorna doméstica, um ciclo testicular anual cujas fases foram consideradas como de repouso no fim do verão; de recrudescência no outono; de proliferação ou maturação celular plena no final do inverno e início da primavera, e, de regressão na primavera e verão ${ }^{10}$.

Quanto aos ritmos reprodutivos de aves, verificaram-se grandes variabilidades dependentes de fatores endógenos ${ }^{11,12,13}$. Estes variam também com a durabilidade do fotoperíodo; pluviosidade e outros fatores climáticos e ambientais, isto é, com fatores exógenos ${ }^{14,15,16,17,18}$.

Em condições de cativeiro, bem como em criações com confinamento de plantéis, no periquito australiano ${ }^{19} \mathrm{e} \mathrm{em}$ anatídeos ${ }^{20}$, há tendência de haver rupturas na constância do ciclo testicular anual de acordo com a duração de luz e o contato vocal entre aves de ambos os sexos. Contudo, no periquito, não se observou regressão testicular e a produção de espermatozóides ocorreu somente quatro vezes durante o ano, alternando-se com períodos de inatividade sexual ${ }^{19}$.

No anatídeo Lophoneta specularioides verificou-se um padrão circanual de alternância de fases de repouso e de atividade testicular, portanto reprodutiva, diferindo dos ciclos espermatogenéticos anuais bem delimitados de aves de regiões temperadas, onde a reprodução é prevalente na primavera $^{20}$. Os autores consideraram que essa espécie de pato andino apresenta um padrão intermediário entre a reprodução contínua e aquela claramente estacional, ou seja, semicíclico. $\mathrm{Na}$ variedade japonesa de codorna ${ }^{10}$, definiu-se um padrão cíclico para a atividade sexual desta espécie, com base em estudos da cinética da espermatogênese.

Assim sendo, com base em observações sobre a histologia e histomorfometria do ducto deferente de codorna doméstica da variedade italiana objetivou-se, neste trabalho, estudar as possíveis variações sazonais deste ducto nas diferentes estações do ano. Ademais, visou-se verificar o tipo de padrão reprodutivo dos machos nesta espécie mantidos durante o ano em confinamento, usando-se plantéis do mesmo sexo com contatos visuais e sonoros com plantéis similares de codornas do sexo feminino. Nestas mesmas condições estudou-se o ciclo testicular anual desta ave doméstica, tendo sido notada quiescência testicular típica no outono ${ }^{21}$.

\section{Materiais e Métodos}

\section{Coleta do material}

Para este trabalho utilizaram-se 12 codornas (Coturnix coturnix) da variedade italiana, machos, adultas, com peso corpóreo médio de 200 gramas, procedentes do criatório experimental de codornas da Fazenda Edgárdia, UNESP/Botucatu. Os animais foram mantidos nos plantéis de criação com dieta sólida e água administradas "ad libitum". Os ductos deferentes de cada 3 codornas foram coletados, respectivamente, nos meses mais expressivos de cada estação, ou seja: final de março a meados de abril (outono), junhojulho (inverno), outubro a meados de novembro (primavera), e janeiro-fevereiro (verão). As codornas foram anestesiadas com uma mistura de cloridrato de quetamina $(20 \mathrm{mg} / \mathrm{kg})$ e cloridrato de xilazina $(1,5 \mathrm{mg} /$ $\mathrm{kg}$ ), obtendo-se eutanásia e a seguir foram feitas laparotomia; evisceração do trato gastrointestinal e coleta dos ductos deferentes, em suas porções proximal (adepididimária), média (justarenal) e distal (adcloacal).

\section{Microscopia de Luz}

A rotina de microscopia de luz foi a 
usual, com fixação do material em solução aquosa de formalina tamponada (tampão fosfato, $\mathrm{pH}$ 7,2, $0.1 \mathrm{M}$ ), fixador de Bouin e fixador de McDowell. Os dois primeiros fixadores citados, foram utilizados para as amostras tissulares destinadas para estudos de microscopia de luz em materiais incluídos em paraplas $€ \mathbb{R}$ e o último usado para aqueles

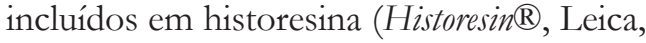
Alemanha). A seguir foram feitas a microtomia com cortes de 5 a $7 \mathrm{~mm}$ no

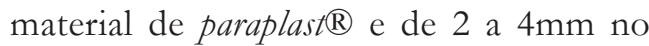
material de historesina, e colorações com $\mathrm{HE}$, azul de toluidina $1,5 \%$ e PAS/H. O material foi analisado com fotomicroscópio Olympus BX-41 (Olympus ${ }^{\circledR}$, Japão) e fotodocumentado com o emprego de câmera digital DP-12 (Olympus $\left.{ }^{\circledR}\right)$.

\section{Histomorfometria}

Para a histomorfometria utilizaramse materiais de microscopia de luz. A histomorfometria foi feita para obter os valores de alturas epiteliais e dos diâmetros tubular e luminal dos ductos deferentes, enfocando-se as análises morfométricas nos segmentos transversais destes ductos, obtidos do segmento médio tubular. Foram utilizadas três lâminas de cada codorna, contendo as lâminas três cortes histológicos, sendo realizadas quatro medidas por corte. As análises histomorfométricas foram feitas através do software Image-Pro version 4.5.1.3 for Windows 98/NT/ME/2000/ XP (EUA), utilizando as imagens captadas através de câmera digital Olympus DP-12 acoplada ao microscópio Olympus BX-41. Os valores obtidos foram agrupados por estação do ano e tratados estatisticamente por métodos paramétricos - valores de médias aritméticas e desvios-padrão ${ }^{22}$.

\section{Resultados}

O ducto deferente de codorna italiana no outono, o período quiescente do ciclo testicular anual, assume um padrão retilíneo aparecendo como um ducto único com a parede mostrando pregas longitudinais ao nível do epitélio de revestimento pseudoestratificado colunar e tendo a luz tubular freqüentemente vazia ou com pouco material de esfoliação celular, nos segmentos proximal (Figura 1a), médio (Figura 2a) e distal (Figura 3a).

Nas demais estações do ano, ou seja, inverno, primavera e verão, os cortes histológicos transversais do ducto deferente de codorna mostram-no organizado como túbulos paralelos entre si (Figura 1b), sendo conseqüentes aos enovelamentos estreitos que o ducto faz sobre si mesmo. Neste caso formam-se "ilhas" de secções tubulares individualizadas, envoltas e mantidas entre si por tecido conjuntivo frouxo periadventicial, sendo cada secção do ducto deferente no conjunto tubular delimitada por tecido frouxo adventicial (Figuras 1b e 3d).

Quando o ducto deferente assume padrão enovelado, a luz tubular freqüentemente estoca grande quantidade de espermatozóides e fluido, o que se observa em todos os segmentos tubulares, nas preparações de inverno (Figuras 1b a 3b), primavera (Figuras 1c a 3c) e verão (Figuras $1 \mathrm{~d}$ e $3 \mathrm{~d})$. A estrutura da parede vaso deferencial, melhor visível nas secções histológicas de outono onde o ducto é retilíneo, é formada por epitélio, lâmina própria que em conjunto formam pregas longitudinais, camada muscular lisa sem estratos bem definidos e camada adventícia predominantemente estruturada por tecido conjuntivo frouxo. Observa-se que a espessura relativa da camada muscular aumenta progressivamente do segmento proximal para o distal (Figuras 1a, 2a e 3a, respectivamente).

Ainda ao assumir padrão enovelado o ducto deferente de codorna nas estações de inverno (Figuras 1b, 2a e 3b), primavera (Figuras 1c, 2a e 3c) e verão (Figuras 1d, 2a e 3d), mostra a parede tubular formada pelos mesmos componentes estruturais descritos no outono, tendo o epitélio pseudoestratificado de revestimento tubular altura ligeiramente mais baixa do que no outono (Figura 4). Aparecem eventuais pregas 
longitudinais (Figuras 1b e 1d) e a lâmina própria (córion) é às vezes característica (Figuras 1c e 1d), ou então, está fundida em extensões variáveis com a túnica muscular (Figsuras 3c). Os tipos celulares do epitélio pseudoestratificado de revestimento deste ducto são as células principais, ou colunares, e as células basais (Figuras 2d). O segmento distal do ducto deferente termina como a "pars recta" deste ducto (Figuras 3d), tendo aparência morfológica similar à do ducto deferente no outono. A parte reta do ducto deferente se abre diretamente na papila vaso-deferencial do urodeo.

Os valores médios dos diâmetros tubular e luminal, mensurados no segmento médio do ducto deferente de codorna, são comparados entre si nas quatro estações do ano. Observam-se pequenas diferenças nos diâmetros tubulares e luminais na primavera, verão e inverno, sendo que nesta estação ambos os diâmetros são um pouco maiores. Porém, as diferenças numéricas observadas nestas três estações não foram significativas entre si. Por outro lado, ocorreu diminuição significativa nos valores médios dos diâmetros tubular e luminal do ducto deferente no outono, relativamente aos das outras estações do ano (Figura 4).

\section{Discussão}

A disposição muito ondulada do ducto deferente de codorna observada na primavera, verão e inverno, exceto no outono, relacionar-se-ia com a maior capacidade de reserva funcional e condução vaso-deferencial de sêmen. Isto, consoante a tese de que os ductos excretores dos testículos em aves, principalmente os ductos deferentes, apresentam mecanismos histofisiológicos e fisiológicos para estocagem e condução de sêmen, incluindo peristalse tubular ativa 7 . A capacidade de reserva funcional de sêmen, e consequentemente de espermatozóides,

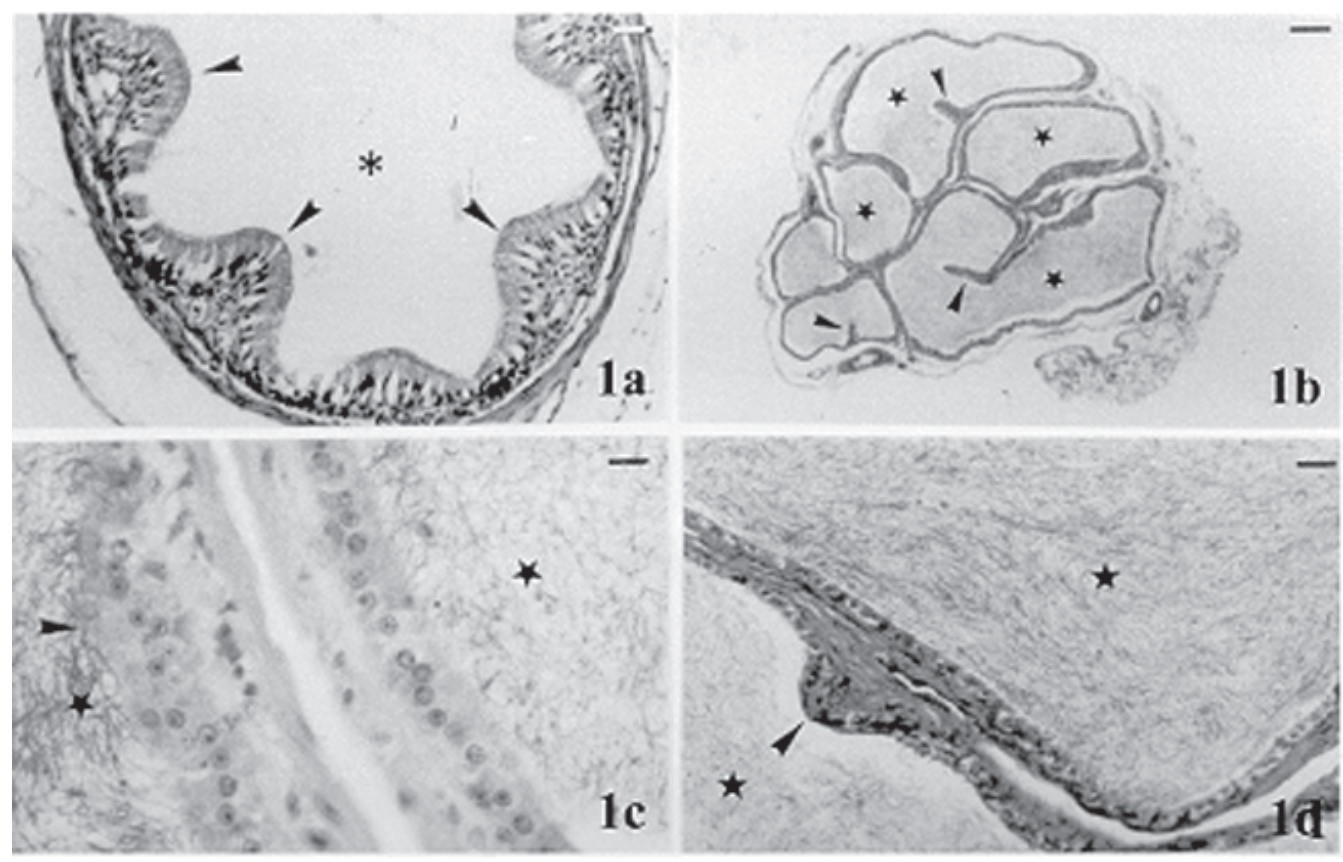

Figuras 1a - d - Fotomicrografias de secções transversais do segmento cranial (adepididimal), do ducto deferente (DD) de codorna italiana no outono (a: 100x, barra: 5 um), inverno (b: 20x, barra: 25 um), primavera (c: 200x, barra: 2,5 um), e verão (d: 100x, barra: 5 um), sendo visualizadas a disposição retilínea do DD no outono (a) e convuluta (b a d), nas demais estações. São indicados: pregas longitudinais da mucosa (cabeças de setas), luz tubular $\left(^{*}\right)$ e conteúdo luminal (estrelas). Hematoxilina-fucsina em a, b e d; HE emc. 


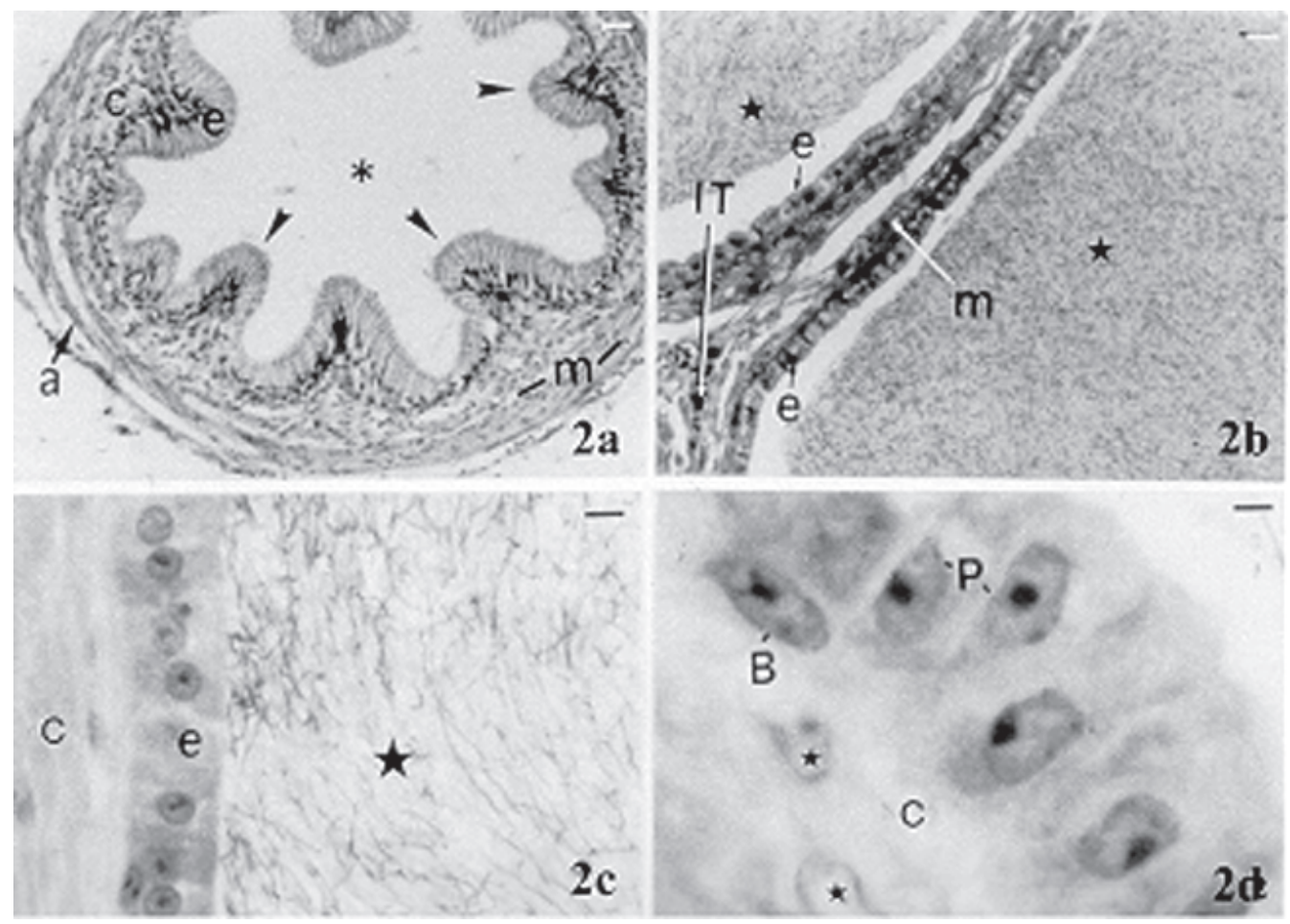

Figura 2-d - Secções transversais do segmento médio (justarenal), do ducto deferente (DD) de codorna italiana no outono (a: 100x, barra: 5 um), inverno (b: 100x, barra: 5 um), primavera (c: 400x, barra: 1,25 um), e verão (d:100x, barra: 0,5 um), sendo indicados: luz tubular (*) e conteúdo luminal (estrelas); pregas longitudinais da mucosa (cabeças de setas) e epitélio tubular (e) com células basal (B) e principais (P); córion (c), muscular lisa (m), vasos sangüíneos (estrelas menores) e adventícia (a). HE, em todas as preparações

certamente diminui no período quiescente de outono, quando o ducto deferente se torna retilíneo e há a quiescência testicular ${ }^{21}$, talvez com conseqüente diminuição da peristalse vaso-deferencial. Contudo, a espessura mural do ducto deferente é marcante no outono, sendo dada pela relativa diminuição da luz tubular que aparece vazia de espermatozóides nesta estação.

No ducto deferente de codorna, a estrutura da parede tubular é formada por camadas superpostas e seqüentes, caracterizando-se: o epitélio de revestimento, lâmina própria, muscular e adventícia bem típicas, como se descreveu no ducto deferente do galo doméstico ${ }^{2}$. O epitélio vaso-deferencial é pseudoestratificado colunar com predomínio de células principais e também a ocorrência de células basais, bem evidentes na dimensão de microscopia de luz como antes já caracterizada em aves 5 .
Referente ainda à estrutura histológica do ducto deferente de codorna, a lâmina própria mural é um estrato delgado, formado predominantemente por tecido conjuntivo frouxo. A túnica muscular lisa é geralmente delgada, talvez em função da expansão tubular e luminal e da intensa concentração de espermatozóides estocados na luz do ducto, durante todas as etapas mais representativas do ciclo testicular anual. Este obedece um padrão cíclico circanual nesta espécie ${ }^{21}$, diferentemente do que se observou em anatídeo ${ }^{20}$.

A codorna doméstica japonesa apresenta espermatozóides na luz dos túbulos seminíferos durante todo o ano ${ }^{10}$, o que aqui não se viu no outono, pressupondo uma atividade gonadal constante. Esta seria regida principalmente por fatores endógenos, ou seja, por influência hormonal e como decorrência natural dos ritmos biológicos, caracterizados em aves ${ }^{12,13}$, do que em 

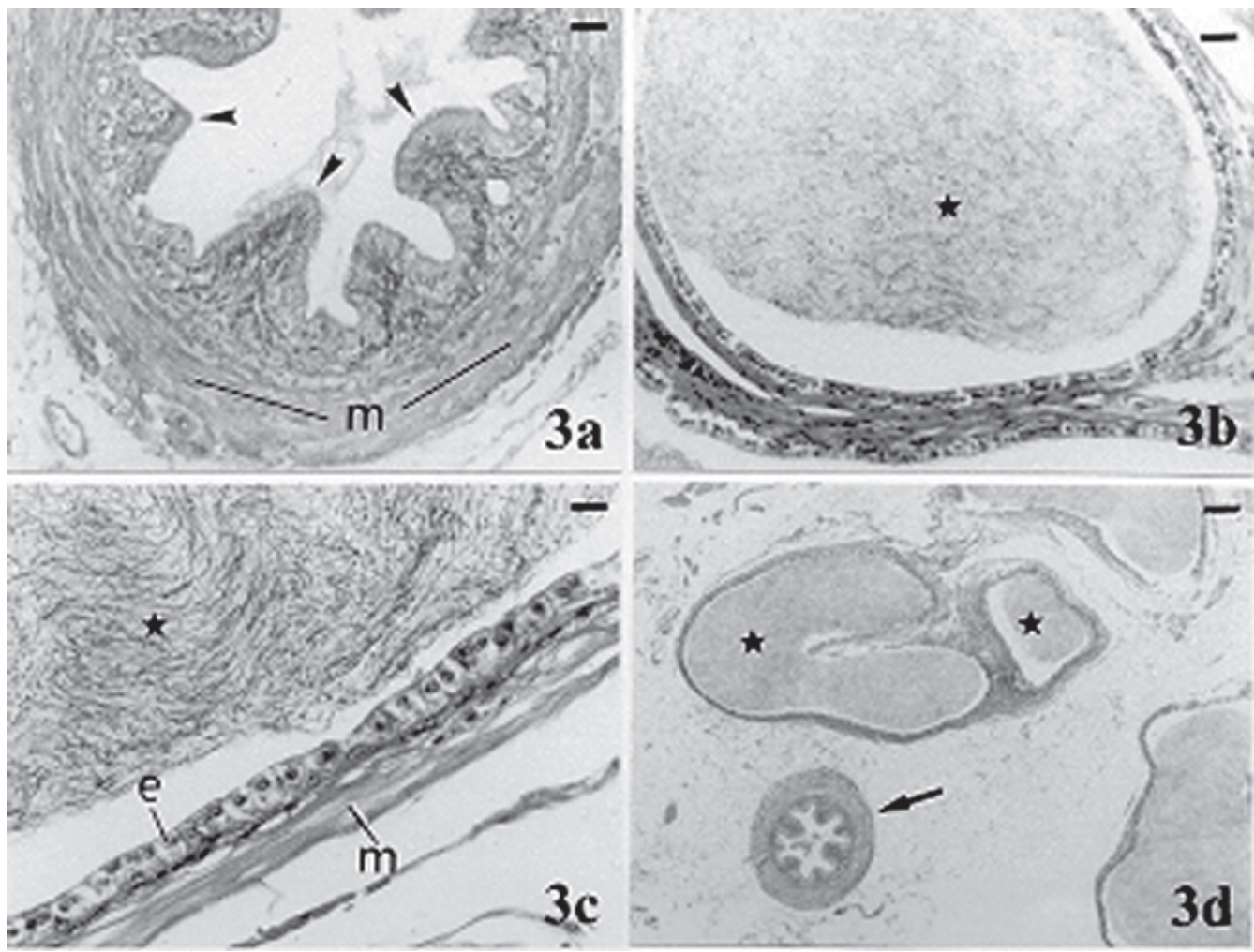

Figura 3 - $d$ - Secções transversais do segmento caldal (adcloacal), do ducto deferente (DD) de codorna italiana no outono (a: 100x, barra: 5 um), inverno (b: 100x, barra: 5 um), primavera (c: 200x, barra: 2,5 um), e verão (d: 20x, barra: 25 um), sendo visualizados a disposição retilínea do DD outono (a) e convuluta (d), no verão. São indicados: conteúdo luminal (estrelas); pregas longitudinais da mucosa (cabeças de setas) e epitélio tubular (e): camada muscular lisa $(\mathrm{m})$ e a parte reta terminal (seta) do DD em d. HE, em todas as preparações.

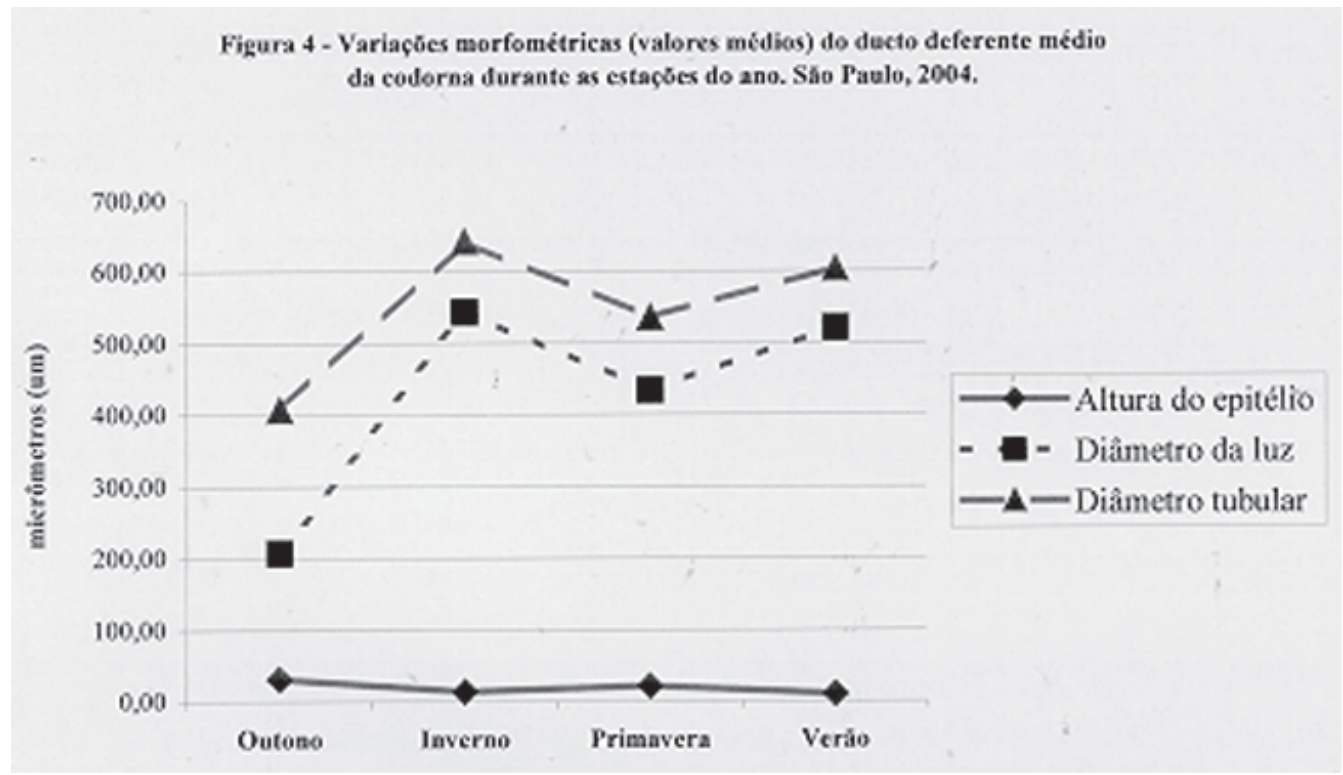

Figura 4-Gráfico mostrando as variações morfométricas da altura epitelial e dos diâmetros tubular e luminal do ducto deferente médioi da codorna durante as estações do ano. 
decorrência direta da ação de fatores exógenos ou ambientais, também influentes ${ }^{20}$.

Mediante outros enfoques, há estudos que questionam a ocorrência de ciclagens testiculares anuais convencionais, ou seja, com quatro fases bem definidas, inclusive em Coturnix coturnix, a espécie aqui estudada, e em algumas outras espécies de aves passeriformes. Assim sendo, o desenvolvimento gonadal eventualmente ocorreria também em dias curtos, durante o outono e inverno, ou seja, em dias de fotoperíodo curto; em constante ausência de luz $z^{23,24}$. Aqui nas observações sobre a morfologia do ducto deferente de codorna, verificou-se um padrão cíclico circanual estacionário no outono mais ativo nas outras estações do ano e diferente daquele descrito na codorna da variedade japonesa ${ }^{2}$.

Em codorna italiana foram definidos dois períodos marcantes: a quiescência outonal com forte expressão em março, e a intensa proliferação primaveril, expressada entre outubro e novembro, em parte concordando com observações anteriores ${ }^{10}$, quanto a quiescência testicular, marcante em março, observada na variedade japônica de codorna estudada pelos autores ${ }^{10}$. Todavia, se ressalva que, aparentemente fora do período outonal bem marcante entre a segunda quinzena de março à aproximadamente meados de abril, a espermatocitogênese não cessou ${ }^{21}$. Assim sendo, se flagrou abundância de espermatozóides intraluminais, ao longo do ducto deferente, como é usual no período de proliferação testicular de aves ${ }^{4}$.

\section{Agradecimentos}

À FAPESP - Fundação de Amparo à Pesquisa do Estado de São Paulo e ao CNPq - Conselho Nacional de Desenvolvimento Científico e Tecnológico, pelo apoio financeiro.

\section{Seasonal study quail's vas deferens of italian variety: morphology and histomorphometry}

\section{Abstract}

In the autumn the vas deferens of the Italian variety of domestic quail appeared as a single, thin, and straight duct along its total extension. Thus, transversal histologic sections of this duct showed a circular tubular shape. The pseudoestratified columnar epithelium that lined the vas deferens presented longitudinal folds which invaded the lumen frequently empty of spermatozoa. Although in the winter, spring and summer the usual morphological appearance of the quail's vas deferens was seen as a highly coiling duct. So, each transversal histologic section of the vas deferens, in all the segments, showed parallel cut sections of the duct being irregular in shape and variable in number and interconnected by the adventitial loose connective tissue. In these observations, the tubular lumen was totally performed by spermatozoa and seminal fluid. Consequently, with previous base on the testis kinetics of the Italian quail variety, it was concluded that the spermatozoa production, followed by emission, storage and ejaculation of spermatozoa through the vas deferens did not stop during the winter, spring and summer, but ceased in the autumn the quiescent phase of the circannual reproductive cycle in this bird.
Key-words: Vas deferens. Morphology. Seasonal variability. Domestic quail. Italian variety.

\section{Referências}

1 AIRE, T. A.; AYENI, J. S.; OLOWO-OKORUN, M.

$O$. The structure of the excurrent ducts of the testis of the guinea-fowl (Numida meleagris). Journal of Anatomy, London, v. 129, p. 633-643, 1979.

2 GRAY, J.C. The anatomy of the male genital ducts in the fowl. Journal of Morphology, Philadelphia, v. 60, 
p. 393-405, 1937.

3 LAKE, P. E. The male reproductive tract of the fowl. Journal of Anatomy, London, v. 91, p. 116-129, 1957.

4 LAKE, P. E. Male genital organs. In: KING, A.S.; MCLELLAND, J. Form and function in birds. London: Academic Press, 1981. v.2.

5 STEFANINI, M. A.; VICENTINI, C. A.; ORSI, A. M.; VICENTINI, I. B. F.; ARTONI, S. M. B. Características morfológicas do ducto deferente do pombo (Columba livia). Revista Brasileira de Biologia, Rio de Janeiro, v. 56, p. 605-612, 1996.

6 TINGARI, M. D. On the structure of the epididymal region and ductus deferens of the domestic fowl (Gallus domesticus). Journal of Anatomy, London, v. 109, p. 423-435, 1971

7 DE REVIERS, M. Sperm transport and survival in male birds. In: Basel: Karger, 1975. The biology of spermatozoa.

8 MANOEL, H. L.; ARTONI, S. M. B.; ORSI, A. M.; STEFANINI, M. A.; ARAUJO, M. L. Aspectos morfométricos do ducto deferente da codorna, Coturnix coturnix japonica, no decorrer do ano. Biotemas, Florianópolis, v. 11, p. 97-104, 1998.

9 ORSI, A. M. et al. O ducto deferente de codorna: estrutura e possíveis variações morfológicas sazonais. In: CONGRESSO BRASILEIRO DE ANATOMIA, 20. 2002, Maceió. Resumos... São Paulo: Sociedade Brasileira de Anatomia, 2002, v. 1, p. 159.

10 ARTONI, S. M. B.; ORSI, A. M.; CARVALHO, T. L. L.; LOPES, R. A. The annual testicular cycle of the domestic quail (Coturnix coturnix japonica). Anatomia, Histologia, Embryologia, Berlin, v. 26, p. 337-339, 1997.

11 FRAISSINET, M.; VARRIALE, R.; PIERANTONI, R. et al. Annual testicular activity in the grey partridge (Perdix perdix L.). General and Comparative Endocrinology, New York, v. 68, p. 28-32, 1987.

12 WINGFIELD, J. C. Control of testicular cycles in the song sparrow, Melospiza melodia melodia: interaction of photoperiod and an endogenous program? General and Comparative Endocrinology, New York, v. 92, p. 388-401, 1993.

13 WINGFIELD, J. C.; WHALING, C. S.; MARLER, P. Communication in vertebrate aggression and reproduction: the role of hormones: male-male interactions in birds. In: KONOBIL, E. Y.; NEILL, J. D. The Physiology of reproduction. 2. ed. New York: Raven Press, 1994, v. 1 p. 310-312.

14 FOLLET, B. K.; SHARP, P. J. Circadian rhythmicity in photoperiodically induced gonadotrophin release and gonadal growth in the quail. Nature, London, v. 223, p. 968-971, 1969.

15 FRITH, H. J.; CARPENTER, S. M.; BRAITHWAITE, L. W. Sexual cycles of pigeons in arid and semiarid
Australia. Australian Journal of Zoology, East Melbourne, v. 24, p. 331-351, 1976.

16 FUENZALIDA, H.; LEYTON, V.; VALENCIA, J. et al. Morfologia del testiculo de Pygoscelis papua (Foster) durante el periodo de actividad sexual. Archivos de Anatomía y Embriología, Madrid, v. 20, p. 79-91, 1989.

17 HAMNER, W. M. Photoperiod control of the annual testicular cycle in the house finch, Carpodacus mexicanus. General and Comparative Endocrinology, New York, v. 7, p. 224-233, 1966.

18 KRUEGER, K. K.; OWEN, J. A.; KRUEGER, C. E.; FERGUSON, T. M. Effect of feed or light restriction during the growing and breeding cycles in the reproductive performances of broad breasted white turkey males. Poultry Science, College Station, v. 56, p. 1566-1574, 1977.

19 SAMOUR, J. H.; MOORE, H. D. M.; BAILEY, I. T.; WATSON, P. F. Annual testicular cycle in captive budgerigars (Melopsittacus undulatus). Journal of Zoology, London, v. 212, p. 465-473, 1987.

20 BREUCKER, H.; SCHAFER, E.; BUSTOSOBREGON, E. Spermatogenesis of Lophonetta specularioides (Anatidae, Aves) in the high plateau of the southern Andes: a light and electron microscopic study. Microscopia Electronica y Biologia Celular, Mendoza, v. 13, p. 167-182, 1989.

21 ORSI, A. M.; STEFANINI, M. A.; VIEGAS, K. A. S.; SIMÕES, K.; ARTONI, S. M. B. Aspectos morfológicos do ciclo testicular anual de codorna doméstica (Coturnix coturnix) da variedade italiana. Brazilian Journal of Medicine Veterinary and Animal Science, São Paulo, In press, 2004

22 MORRISON, D. F. Multivariate statistical methods. Tokio: Kogakusha, 1976

23 GUYOMARC'H, C.; GUYOMARC'H, J. C. Sexual development and free-running period in quail kept in constant darkness. General and Comparative Endocrinology, New York, v. 86, p. 103-110, 1992.

24 SHARP, P. J.; STERLING, R. J. Photoperiodic requirement for the dissipation of scotorefractioriness in Japanese quail. General and Comparative Endocrinology, New York, v. 58, p. 169-173, 1985.

25 CLULLOW, J.; JONES, R. C. Studies of fluid and spermatozoa transport in the extratesticular genital ducts of the Japanese quail. Journal of Anatomy, London, v. 157 , p. 1-11, 1988.

26 VIOTTO, M. J. S.; ORSI, A. M.; GREGORIO, E. A. Ultrastructural characteristics of the epididymal epithelium of the cat (Felis domestica, L.). Brazilian Journal of Morphological Sciences, São Paulo, v. 13, p. 51-58, 1996. 